\title{
The Behavior of Suppliers in Supplier-Customer Relationships
}

\author{
Ralph Riedel, Norbert Neumann, Marco Franke, and Egon Müller \\ Chemnitz University of Technology, Department of Factory Planning and Factory Opera- \\ tions, D-09107 Chemnitz, Germany and Robert Bosch GmbH, Chassis System Control, \\ Blaichach, Germany \\ ralph.riedel@mb.tu-chemnitz.de, norbert.neumann@de.bosch.com, \\ marco.franke@mb.tu-chemnitz.de, egon.mueller@mb.tu-chemnitz.de
}

\begin{abstract}
Suppliers have become resources for innovation and competitive advantages. To realize those potentials specific competencies have to be developed in a partnership between customer and supplier. The success of those development projects and also the effort that has to be put in depend on several factors. One of those factors is the motivation of the supplier organization. An empirical study shows that the motivation can be described sufficiently exactly by particular characteristics. Moreover particular influencing factors with significant impact on supplier motivation could be extracted. Those findings can be used to control supplier development projects better which in turn will lead to qualitatively better results and a better cost-benefit ratio.
\end{abstract}

Keywords: Keywords: supplier development, supplier motivation, supplier relations.

\section{Introduction}

The interface between supplier and customer has seen a constant change over the last three decades. In the 1970s customer focused primarily on reliable supply and price and neglected other criteria for supplier selection. [1] In the following years companies outsourced higher and more complex value adding process steps to their suppliers. [2] This trend intensified the cooperation between customer and supplier. In the beginning customers started to target quality and innovation performance. Later on customers tried to integrate suppliers closer and closer into their product development process. [3] The main objective of this integrated supply management is getting the best value out of the close linkage through optimized product and process design for both parties. Frontrunners of this development are electronics and automotive industry.

As a result the criteria for supplier selection changed over time. Today customers want to know if suppliers are able to act proactively and will recognize their needs. This can be shown for instance by the commitment to zero defects quality processes and best price quotes. [4] In reality customers know that those expectations can rarely be found. [5]

One way to improve the performance level of suppliers in the described direction is supplier development. This is conducted in many industries by the customers itself or 
by consulting companies in close cooperation with the customer. Well known approaches are the activities of Japanese electronics and automotive companies which are accomplished within Keiretsu structures. The outstanding success of the Japanese industry of the last decades is based to a certain extend on this kind of integrated supplier integration into the holistic value adding process. [6]

Although, one aspect is different in Japanese industry compared to Europe or the US. Japanese Keiretsu suppliers are generally motivated for the development by the customer. This results from the special cultural context of Japanese industries. Normally the supplier fears that in a development project the customer acquires too much insider know-how. If this happens it would be possible for the customer to use this know-how price negotiations or, even worse, by transferring it to other companies for building up an alternative supply source.

In this respect it is difficult that the motivation of suppliers with regard to potential development projects cannot be easily verified before the start of a project. Normally both motivated as well as non motivated supplier signal interest in the proposed development projects. In the existing phase of integrated supplier management it is nearly impossible for a supplier to refuse the wish of a customer for a development project. Non motivated suppliers behave comparable to children in front of Santa Claus. They promise to behave according to the wishes of the customer in the next time. Later on they may show a different behavior with the objective to minimize the information flow to the customer during the project which typically lasts between 6 to 18 months. For the customer this behavior means the worst case in respect of his original target. Instead of getting a benefit out of a developed supplier through a stable and productive process and a resulting lower price, better quality, innovations or increased logistics performance the result is the waste of his (the customer's) valuable supplier development resources.

Therefore it is essential to use the supplier development resources efficiently. This must be supported by the identification for the actual supplier motivation before the projects starts. The objective of the study presented here is the development of a method for the analysis and prediction of supplier's motivation for development projects as one important dimension of a supplier-customer-relationship.

\section{Supplier Relationship Management}

We started this study by searching an existing scientific base for the given context. As we realized that we have to look generally on influencing factors for customer supplier relationship we focused on Supplier Relationship Management (SRM). SRM is a part of overall Supply Chain Management (SCM). [7] The explicit use of the expression Supply Chain Management started in the 1990s in the North American industry. The objective was to realize more optimization potential in the overall value adding process. The main focus at the beginning of the activities was in many cases the optimization of logistic processes of information and materials. [8] This was also one reason for the establishment of the term Supply Chain Management. Defined and standardized steps should support the realization of the idle potentials in the total value adding process. Hereby Supplier Relationship Management focuses on part of direct interaction with potential and defined suppliers. Since for a long time a static 
consideration of customer supplier relationships was used these considerations became more and more dynamic at the end of the 1990s. [9] Thus these premises changed the role of a supplier from an unchangeable element of the value adding process towards a potential resource which can be influenced through defined actions. [10] Here we also find the starting point for supplier development activities outside of Japan.

One momentum for doing this was the study about the "Second revolution of the automotive industry", which showed systematically advantages of Japanese carmakers versus their American and European competitors. [11] These considerations showed positive as well as negative impacts of supplier behavior on the customer. Negative effects mainly occur by one sided dependencies of a supplier from a customer or vice versa. This can be identified in reality by supplier or customer monopolies. Generally these situations lead to opportunistic behavior which reduces the overall value of the whole supply chain. [12] The theoretical basis for those considerations is provided by institutional economics and transaction cost theory. [13-15]

Fig. 1 shows the important elements of Supply Chain Management and Supplier Relationship Management.

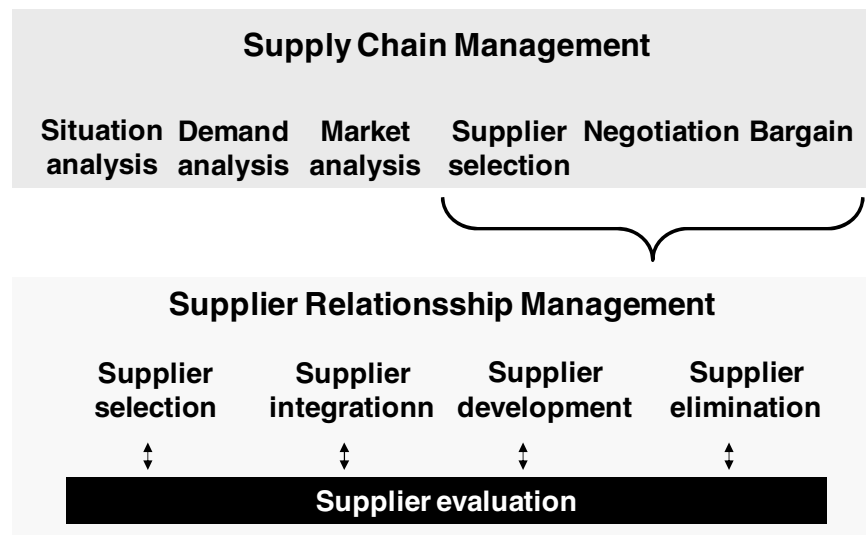

Fig. 1. Elements of Supply Chain and Supply Relationship Management

An important basis for Supplier Relationship Management is the instrument of supplier evaluation. [16] A systematic approach for supplier evaluation should deliver all relevant information a customer needs to start, develop, continue or end a business relationship with a supplier. Since many customers use the instrument of supplier evaluation at the starting point of a relationship it is only rarely used during an already established relationship. [17] Especially as an instrument for defining candidates for supplier development processes there is no method in practical use.

\section{Research Question}

Based on the discussion above, it becomes obvious that for all partners involved in a supplier-customer-relationship it would be essential to know the factors that influence 
the quality of the relationship. Of special interest are the factors that influence the quality, effectiveness, efficiency and sustainability of supplier development projects. Sustainability means in this context that the process improvement is adapted and autonomously maintained by the supplier after the project initiated by the customer and processed with the support of customer's resources ended.

As was discussed too, the behavior of the partners, especially the supplier, in development projects may be driven by its motivation. Motivation plays an important role in explaining human behavior. Motivation is seen as the internal condition that activates behavior and gives it direction; energizes and directs goal-oriented behavior.

Motivation is the psychological feature that arouses an organism to action toward a desired goal; the reason for the action; that which gives purpose and direction to behavior. [18] Motivation is a multivariate concept for the explanation of behavior. [19] The concept consists of the variables person, environment and transaction and its scope covers cognitive as well as behavioral aspects. For the analysis and explanation of motivation several models exist, see for instance [20-22].

Since organizations are led by people, processes and projects are carried out by people it seems to be reasonable to apply the concept of motivation also to a supplier organization. It needs to be recognized that this application is only valid in the scope of this study. Hereby it should be possible to analyze and explain the behavior of the supplier in supplier development projects. Supplier motivation in this context therefore was defined as "the perceived status of internal readiness of a supplier with respect to its sustainable behavior according to the objectives of the development project."

The interesting questions for our study are

1. How can the behavior of the supplier in a supplier - consumer relationship, especially the motivation in development projects, be described? This relates merely to the dimensions that characterize the behavior.

2. Which factors influence the characteristics of the behavior? By knowing those factors is should become possible to explain and to predict a certain behavior.

\section{Methodology}

As a first step a model for the behavior of a supplier in a supplier customer relationship was developed. This model contained several dimensions and characteristics as well as a scale for the motivation of the supplier which was the main focus. The dimensions of the characteristic were derived from literature and also from a workshop with experts in supplier evaluation and development.

Those dimensions and characteristics were then empirically analyzed. The empirical basis of the study consists of data from 60 suppliers of a leading automotive 1st tier supplier. By a factor analysis those dimensions and characteristics were extracted that were able to reliably describe the behavior of the supplier. As a result is was possible to reduce the amount of items and dimensions for the description of the motivation. At the same time the scale for the motivation was validated.

In a second step possible factors were worked out that might have an influence on the behavior of the supplier in a supplier customer relationship. There has been some research on such factors that could be used in this study, see for instance [23-26]. Those factors were also investigated empirically. The data for those factors were 
collected for the same 60 suppliers as were used for the aforementioned analysis. By a factor analysis and a discriminant analysis those factors were extracted that significantly influence the behavior of suppliers. As a result those factors could be extracted that have a significant influence on the motivation of the supplier.

The empirical investigation was done with the help of two questionnaires each containing a multitude of items for the different characteristics and dimensions and the influencing factors respectively. Furthermore quantitative data describing particular internal and external factors (size, turnover, portion of turnover with particular customers, etc.) were analyzed.

\section{Results}

The results gained with the project are interesting and suitable for practical application. They describe motivation in five dimensions or more simple one rating status. The workshop with a brainstorming at the beginning of the process had the objective of finding prospective characteristics and factors that would be able to describe the motivation of suppliers as well as influencing criteria from inside or outside.

For the description of motivation 34 characteristic variables were found e.g. candidness, fair feedback, quality of project management, commitment of the top management and so on. These characteristics were arranged content related in five groups, namely corporate strategy, reliability, credibleness, initiative and cooperation culture.

On the other hand more than 80 influencing factors were initially extracted from the expert workshop as well as from literature. Some of these factors are based on experience e. g. role of the owner, managerial style, and experiences with costumers and corporate projects. Those factors could only be captured subjectively. Some other factors are more measurable or objective e.g. legal form, turnover, market position. These factors were arranged in 14 groups, e. g. products, market, future, strategy and so on. In a later discussion the structure was reduced to six groups. The number of factors could be reduced from 80 to 54 by requirements definition. Requirements had been easy access, objectivity, stability and applicability for statistic evaluations. The objective was the decrease of the number of items regarding to data collection.

The characters and factors were then transformed into items. On average each characteristics variable got three items. Measurable factors were taken from other sources. Experience based factors got one or two items. This means that some 180 items/questions had to be answered during the data collection with the questionnaires. Caused by the quantity of items/questions the data collection was shared into two phases - the first phase for characters and a second one for influencing factors.

After the first phase the data analysis delivered interesting results. The correlation analysis showed that 32 items are suitable for the aspired model. For these items the correlation coefficients differed from 0.369 to 0.511 and for these items the correlation was significant on a 0.01 level. A factor analysis arranged the items in 3 new groups. They differed completely from the original content related groups. The groups got new designations as "holistic acting and understanding", "quality of cooperation" and "systematic of acting". 
During the statistic analysis of phase one's data the second data collection phase took place. After its finish the same statistic methods had been used to analyze these data. The results were astonishing. The results show that only the factors based on experiences are suitable. The correlation coefficients differed from 0.351 to 0.552 and the correlation was significant. Regarding the measurable factors no significant correlation could be shown. That's why only 10 items from the factors part were used for the model. They were arranged in two groups called "experience and perception" and "initiative and business acting" as a result of the factor analyses. As well as the characteristic variables those groups are completely new regarding their composition.

Both analyses showed that the suppliers can be classified only in "motivated" or "not motivated". "Possibly motivated" suppliers could not be found.

After the configuration a prototype of the model had been validated in two steps. For the first step the original data had been used. The objective was to show the consistence of the model. The reliability achieved some $80 \%$. That means that $80 \%$ of the suppliers were classified in the right way. In the second step the model was applied to evaluate the same suppliers that were used for the study for the second time. The results revealed that 60 percent had been classified like in the original way.

Furthermore the validation results showed that the range of rating is characterized by overlaps between "not motivated" and "motivated" suppliers. With respect to this situation and to the desired validity the range of overlaps is now called "possibly motivated". As a consequence for practical application most of the suppliers (namely 21) are classified as "motivated". Only four suppliers are classified as "not motivated". Caused by the aforementioned different ranges between "motivated" and "not motivated" a number of 10 suppliers are "possibly motivated". The following spider graph (Fig. 2) shows the average rating across all suppliers arranged in the five new groups classified form "not motivated" to "motivated".

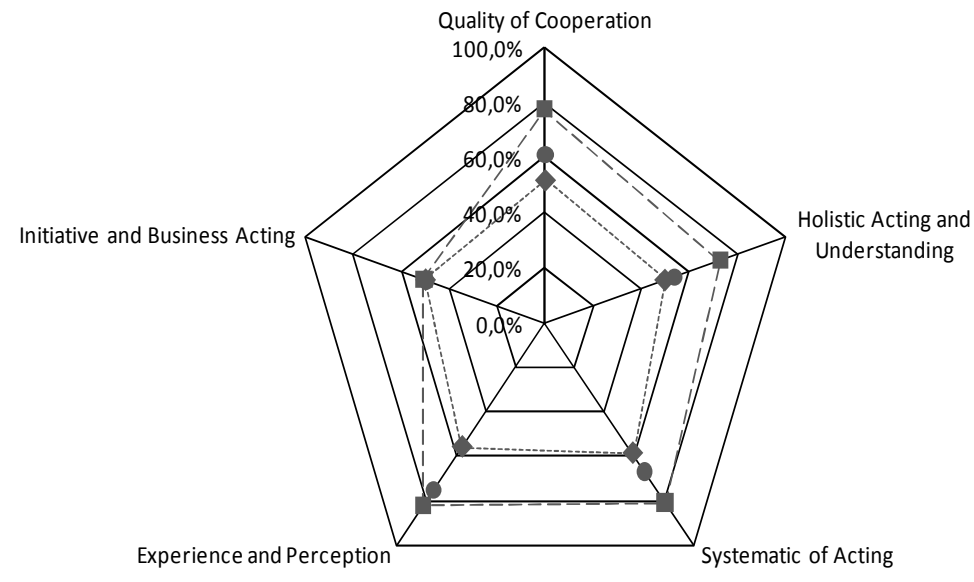

- possibly motivated $\quad---\cdot$ motivated $\quad-----$ not motivated

Fig. 2. Classification of Suppliers according to the developed model 


\section{Conclusion and Outlook}

With the study we could show that it is possible to identify the motivation of suppliers in development projects and to describe those factors having an impact on the motivation. Hereby it will be possible to evaluate and to measure the influencing factors. These insights in turn can be used

1. to predict the probability for the success of development projects under given circumstances

2. to actively influence factors with a hindering characteristic

3. to predict the effort needed to make a project successful

The results of the motivation and factor evaluation could be included into Supplier Relationship Management. By using the evaluation results development projects can be focused on those that promise the most success or the best cost-benefit ratio. Moreover it would be possible to give some feedback to the supplier regarding his motivation so that certain characteristics, factors or the whole relationship can be specifically changed.

\section{References}

1. Theisen, P.: Grundzüge einer Theorie der Beschaffungspolitik. Berlin (1970)

2. Arnold, U., Eßig, M.: Sourcing Konzepte als Grundlage der Beschaffungsstrategie. In: WiST 2000, pp. 122-128 (March 2000)

3. Van Weele, A.: Purchasing \& Supply Chain Management, London (2005)

4. Glatschnig, E.: Merkmalsgestützte Lieferantenbewertung, Köln (1994)

5. Bratzler, M.: Technologiekooperation mit Lieferanten. In: Boutellier, R., Wagner, S.M., Wehrli, H.P. (eds.) Handbuch der Beschaffung, pp. 603-629. Carl Hanser Verlag, München (2003)

6. Imai, M.: Gemba Kaizen. Wirtschaftsverlag Langen Müller/Herbig, München (1997)

7. Ballou, R.: Business Logistics/Supply Chain Management. Planning, Organizing and Controlling the Supply Chain, Upper Saddle River (2004)

8. Wildemann, H.: Supply Chain Management, TCW, München (2000)

9. Knapp, T., Bichler, K.: Permanente Bewertung von Lieferanten. In: Beschaffung Aktuell 2000, pp. 42-47 (December 2000)

10. Ahlström, P.: Presenting qualitative research: convincing through illustrating the analysis process. Journal of Purchasing \& Supply Management 13, 216-218 (2007)

11. Womack, J., Jones, D., Roos, D.: The machine that changed the world. Rawson Associates, New York (1990)

12. Ellram, L., John, N.: The Role of the Purchasing Function: Toward Team Participation. The International Journal of Purchasing and Materials Management 3, 3-9 (1993)

13. Neumann, v.J., Morgenstern, O.: Theory of Games and Economic Behaviour. University Press, Princeton (1944)

14. Williamson, O.: The Economic Institutions of Capitalism, New York (1985)

15. Stölzle, W.: Industrial Relationsships. Oldenbourg Verlag, München (1999)

16. Monczka, R., Trent, R., Handfield, R.: Purchasing and Supply Chain Management. South Western, Mason (2005) 
17. Gofin, K.: Supply base management - an empirical investigation. Cranfield School of Management, Cranfield (1996)

18. Princeton University, http: / / wordnetweb. princeton . edu

19. Katzell, R.A.: Attitudes and Motivation. In: Meltzer, H., Nord, W.R. (eds.) Making Organizations humane and productive, New York (1981)

20. Klein, H.J.: An Integrated Control Theoy Model of Work Motivation. Academy of Management Review 14(2), 150-172 (1989)

21. Hackman, J.R., Oldham, G.R.: Motivation through the design of work: test of a theory. Organizational Behaviour and Human Performance 16, 250-279 (1976)

22. Ajzen, I.: The theory of planned behavior. Organisational Behavior and Human Decision Processes 50, 179-211 (1991)

23. Bakkera, E.F., Kamann, D.-J.F.: Perception and social factors as influencing supply management: A research agenda. Journal of Purchasing \& Supply Management 13, 304-316 (2007)

24. Das, T.K., Teng, B.: Between trust and control: Developing confidence in partner cooperation in alliances. Academy of Management Review 23, 491-512 (1996)

25. Lee, C.W., Kwon, I.-W.G., Severance, D.: Relationship between supply chain performance and degree of linkage among supplier, internal integration, and customer. Supply Chain Management: An International Journal 12(6), 444-452 (2007)

26. Li, S., Lin, B.: Accessing information sharing and information quality in supply chain management. Decision Support Systems 42, 1641-1656 (2006) 